\title{
Modeling of the fuel system of a boiler turbine power plant with a homogenizer mixer to optimize the physical and chemical properties of fuel
}

\author{
Valentin Kotov ${ }^{1}$, Viktor Barskov², Viktor Rassokhin², Victor Chernikov², Anatolii \\ Smetankin $^{2}$, Oksana Nikiforova ${ }^{2}$, Konstantin Andreev ${ }^{3}$, Nikolay Kortikov $^{3}$ \\ ${ }^{1}$ Military training and research center of the Navy "N. G. Kuznetsov Naval Academy", Pushkin, Saint \\ Petersburg \\ ${ }^{2}$ National Technology Initiative Center for Advanced Manufacturing Technologies based on the \\ Institute of Advanced Manufacturing Technologies of Peter the Great St. Petersburg Polytechnic \\ University, Polytechnicheskaya, 29, St.Petersburg, 195251, Russia \\ ${ }^{3}$ Peter the Great St. Petersburg Polytechnic University, Polytechnicheskaya, 29, St.Petersburg, \\ 195251, Russia
}

\begin{abstract}
Improving the technical, economic, and environmental performance of the power plant is the most important direction for improving the characteristics of the ship's propulsive complex. This issue can be solved most effectively by improving the design, repair, and maintenance of the fuel supply system, which significantly affects the quality of the fuel equipment and determines the working process of the steam boiler. Performance indicators of fuel equipment are determined not only by the stability of its design and adjustment parameters and parameters of the fuel supply process, but also by the physical and chemical composition of the fuel.
\end{abstract}

\section{Introduction}

The fuel system of a boiler-turbine power plant is a complex pipeline consisting of a main line and branches from it. The highway consists of sections in the form of simple pipelines, each of which is characterized by constant specified characteristics along the length [1-4].

The schematic diagram of the conditional fuel pipeline of the power plant is shown in figure 1. As part of the fuel pipeline, the following simple pipelines or design sections can be distinguished:

I-fuel pump suction;

II-from the fuel pump discharge flange to the flange behind the release valve;

III - from the fuel pump release valve flange to the oil heater;

IV-from oil heater to fuel filters;

$\mathrm{V}$ - from fuel filters to the control panel;

VI-from the control panel to the boiler injectors.

*Corresponding author: viktorbarskov@mail.ru 
The fuel system also includes permanent hydraulic resistances: disconnecting valves, oil heater, fuel filters, control panel (fuel control valve of the fuel pressure regulator).

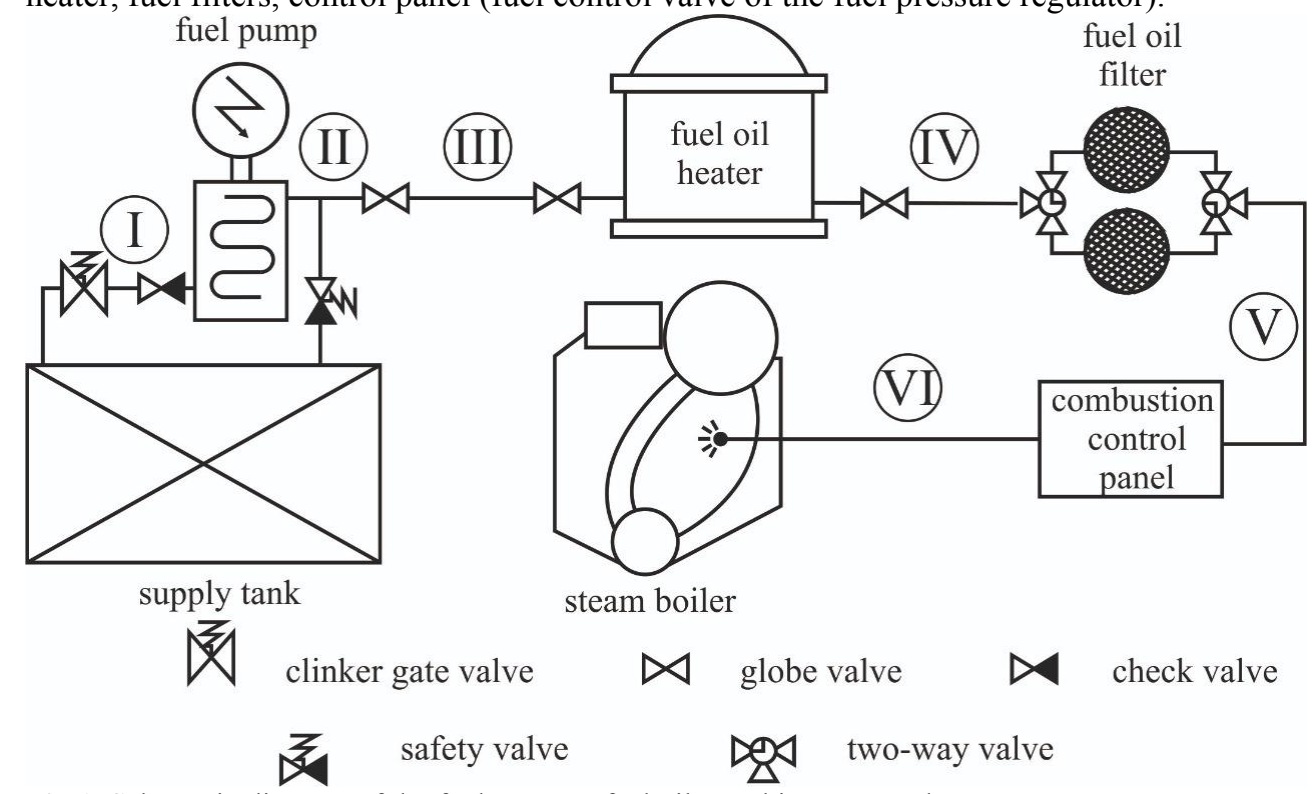

Fig.1. Schematic diagram of the fuel system of a boiler-turbine power plant.

\section{Methods}

The first section is characterized by a constant fuel consumption characteristic $Q_{\text {topl }}=$ const. The hydraulic resistance of the section is determined by the specific gravity, temperature, and viscosity of the fuel. The specific weight of fuel is a parameter that determines the discharge pressure of the fuel pump according to [4]:

where:

$$
p_{0}=p_{\text {stand }} \frac{\gamma_{0}}{\gamma_{\text {stand }}}
$$

$\mathrm{P}_{0}, \mathrm{P}_{\text {stand }}$ is the actual discharge pressure of the fuel pump and when using standard fuel;

$\gamma 0, \gamma_{\text {stand }}$ is the actual and standard specific gravity of the fuel.

In the first section, the fuel temperature is close to the temperature of the beginning of structure formation. The curve of the dependence of the viscosity on the fuel temperature increases sharply when the temperature decreases [5].

The capacity of the fuel pump is also determined by the specific volume of the fuel [4] in law, regulation fuel pump $\mathrm{Q}_{\text {topl }}=$ const at rotation speed $n=$ const dependence of the pump power from specific volume has the form:

where:

$$
N_{0}=N_{\text {stand }} \frac{\gamma_{0}}{\gamma_{\text {stand }}}
$$

$\mathrm{N}_{0}, \mathrm{~N}_{\text {stand }}$ - the actual power of the fuel pump and when pumping standard fuel.

The second section is characterized by a constant flow rate $\mathrm{Q}_{\text {topl }}=$ const at the beginning of the section and a variable flow rate $\mathrm{Q}_{\text {topl }}=$ var at the end of the section at the discharge pressure of the fuel pump $\mathrm{p}_{0}=$ const. The flow characteristic is determined by the boiler load. Flow control is carried out by draining excess fuel into the fuel tank through a safety valve configured for fuel pressure. The specific gravity, temperature, and viscosity of the fuel is the same as in the first section. 
The third section is a simple pipeline with constant hydraulic resistances in the form of turns of the pipeline and disconnecting fittings. It is characterized by a variable flow rate $\mathrm{Q}_{\text {topl }}=\mathrm{var}$ at a constant fuel pressure $\mathrm{p}_{0}=$ const. The specific volume, temperature, and viscosity of the fuel are the same as in the first and second sections.

The fourth section is characterized by a change in the specific weight of the fuel and the viscosity-temperature characteristics of the fuel due to heating the fuel in the oil heater. $\mathrm{Q}_{\text {topl }}=$ var at constant fuel pressure $\mathrm{p}_{\mathrm{II}}=$ const.

The fifth section is distinguished from the fourth by a significant change in fuel pressure due to pressure loss on the fuel filter, which is a constant hydraulic resistance. $\mathrm{Q}_{\mathrm{topl}}=$ var at constant fuel pressure $\mathrm{p}_{\mathrm{III}}=$ const.

The sixth section has a flow characteristic $\mathrm{Q}_{\mathrm{topl}}=\mathrm{var}$ at fuel pressure $\mathrm{p}_{\mathrm{v}}^{\prime}=\mathrm{var}$, which is carried out by throttling the fuel on the fuel spool of the control panel controller.

Thus, the fuel system of a power plant can be divided into sections with a constant flow rate $\mathrm{Q}_{\text {topl }}=$ const at a constant fuel pressure $\mathrm{p}_{\mathrm{i}}=$ const; sections with a variable flow rate $\mathrm{Q}_{\text {topl }}=$ var at a constant fuel pressure $\mathrm{p}_{\mathrm{i}}=$ const and sections with a variable flow rate $\mathrm{Q}_{\text {topl }}=\mathrm{var}$ at a variable fuel pressure $\mathrm{p}_{\mathrm{i}}=$ var.

To solve the problem of determining the level of potential energy of the fuel flow behind the fuel pump, which can be operated on a homogenizer mixer, we can consider the hydraulic characteristics of the I-V sections, where $\mathrm{p}_{\mathrm{i}}=$ const is provided. The fourth section has a hydraulic characteristic determined by the law of fuel consumption regulation, adopted to ensure fuel supply to the boiler furnace. The flow characteristic of the fourth section is strictly determined by the lower limit of the pressure value in front of the control panel and is regulated by throttling on the spool of the fuel pressure regulator.

When using standard fuel, the characteristics of the first and beginning of the second section are constant. the Volume fuel consumption, regardless of the temperature and viscosity of the fuel, is a constant value determined by the performance of the fuel pump. The viscosity-temperature properties of the fuel determine only the hydraulic resistance at the suction of the fuel pump. Therefore, the solution of the problem is reduced to determining the hydraulic characteristics at the end of the second section and at the third and fourth sections of the fuel system of the power plant.

To determine the hydraulic characteristics of the selected sections, it is necessary to solve a static problem for the nominal operating mode of the boiler-turbine power plant, since it is necessary to determine the minimum reserve of potential energy of the fuel flow. To construct a mathematical model of the fuel pipeline, it is advisable to apply the method of equivalent lengths [6]. This is due, firstly, to the use of pipelines of the same diameter throughout all the sections under consideration, and secondly, to the significant influence of viscous friction forces during fuel movement.

The consumption characteristic of the fuel system is determined not by the performance of the fuel pump $Q_{\text {pump}}$, which is an indicator of volume flow, but by the required amount of fuel for the operation of the boiler-turbine power plant at the rated load $\mathrm{Q}_{\text {topl, }}$, which is an indicator of mass flow. Therefore, the construction of a mathematical model is based on the mass consumption of fuel through the pipeline. At the rated load of the boiler-turbine power plant $\mathrm{Q}_{\text {topl }}=\gamma \mathrm{Q}_{\text {pump }}$, where $\gamma$ is the specific weight of the fuel. That is, the pump capacity fully ensures the operation of the power plant.

\section{Results and Discussion}

At the nominal operating mode of the boiler-turbine power plant, all fuel goes to the control panel, the safety-bypass valve is closed. The flow rate through the drain is assumed $q_{c r}=0$,

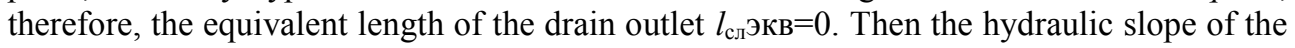
second section will be defined as: 
where:

$$
i=\frac{\lambda \omega^{2}}{d 2 g}
$$

$d$ is the diameter of the pipeline;

$\omega=\frac{4 Q_{\text {mons }}}{\pi d^{2} v \gamma}$ - fuel flow rate;

$\lambda$ is the coefficient of hydraulic friction, defined in accordance with [6] for Reynolds numbers $R e>2320$ as:

and for $\operatorname{Re}<2320$ :

$$
\lambda=0,1\left(1,46 \frac{k_{\ni}}{d}+\frac{100}{R e}\right)^{0,25}
$$

$$
\lambda=\frac{64}{R e}
$$

The Reynolds number is determined by the flow characteristic of the pipeline:

where:

$$
R e=\frac{4 Q_{m o n л}}{\gamma \pi d v}
$$

$v$ is the kinematic viscosity coefficient of the fuel.

The value of the local resistance coefficients $\zeta$ [3] determines the sum of the equivalent lengths of local resistances (for the second section under consideration, this will be the fuel pump discharge valve):

$$
\begin{aligned}
& \text { The reduced length of the second section will be: } \\
& \qquad l_{\text {npII }}=l_{I I}+l_{\text {III }}
\end{aligned}
$$

$$
l_{\ni I I}=\sum \zeta_{i} \frac{d}{\lambda}
$$

The pressure loss in the second section is defined as:

$$
\nabla p_{I I}=i l_{\text {пр } I}
$$

Then the pressure behind the fuel pump discharge valve will be:

where:

$$
p_{2}=p_{0}-\nabla p_{I I} \gamma
$$

$p_{0}$ - fuel pump discharge pressure when pumping standard fuel.

Modeling of the third section of the fuel system:

The fuel section ends at the entrance to the oil heater. The oil heater is a constant hydraulic resistance. At the same time, when the fuel passes through the oil heater, the temperature, specific gravity and viscosity of the fuel change significantly. The oil heater can be a heat exchanger with the passage of fuel in the inter-tube space, it can also consist of either one or more sections of vertical ascending-descending finned outside pipelines with a 180-degree rotation in each section, or it can. Sectional oil heaters are usually made of a steel pipeline of the same diameter as the diameter of the fuel system pipeline.

To build a model of the third section, we assume that, firstly, the oil heater is a sectional one with a pipeline with a diameter equal to the pipeline of the fuel system, and secondly, that the fuel is heated instantly at the outlet of the oil heater. This assumption is correct when calculating the stationary mode of boiler-turbine power plant operation. The hydraulic calculation of the systems gives an overall accuracy of 10\%. [6].

Then the calculation of the third section is reduced to determining the reduced length of the pipeline, since the hydraulic slope i remains unchanged.

where :

$$
l_{\text {ЭIII }}=\zeta_{\text {пов }} \frac{d}{\lambda}+\sum \zeta_{j} \frac{d}{\lambda}
$$

$\zeta_{\text {nos }}$ - local resistance of the oil heater rotation by 180 degrees; 
$\zeta_{i}$ - coefficients of local resistances that are part of the third section. The reduced length of the third section will be defined as:

where:

$$
l_{n p I I I}=l_{I I I}+l_{\text {IIII }}+l_{\text {un }}
$$

$l_{I I I}$ is the length of the pipeline of the third section;

$l_{u n}$ - length of the oil heater pipeline.

The pressure loss in the third section will be:

The fuel pressure behind the oil heater will be:

$$
\nabla p_{I I I}=i l_{n p I I I}
$$

$$
p_{I I I}=p_{I I}-\nabla p_{I I} \gamma
$$

The adopted model of the third section allows us to estimate the pressure loss on the section with sufficient accuracy. Changes in the specific gravity, viscosity, and temperature of the fuel in the oil heater that are not accounted for in the model can be ignored, since the model is based on the mass fuel consumption. Heating fuel leads to an increase in volumetric flow through the pipeline due to reduced specific gravity when heated, and, consequently, to increase the rate of flow of fuel. High flow rates with a decrease in viscosity lead to a decrease in the hydraulic slope $i$ [3], that is, to a decrease in head loss.

Modeling of the fourth section of the fuel system. Fourth section is characterized by changes in the viscosity and volume characteristics of the fuel due to its heating in the oil heater. The fuel flow rate changes accordingly.

The change in specific gravity can be described by empirical dependence through a change in the fuel density [7]

where:

$$
\rho_{2}=\frac{\rho_{1}}{1+\alpha(\rho)\left(t_{2}-t_{1}\right)}
$$

$\rho_{1}, \rho_{2}$ is the fuel density at temperatures $t_{1}$ and $t_{2}\left(\rho=\gamma / 9,81 \mathrm{kgf}^{2} / \mathrm{M}^{4}\right)$;

$\alpha(\rho)$ is the coefficient of volumetric expansion of the fuel when heated.

The dependence of the fuel viscosity on the temperature $v(t)$ can also be represented by an analytical dependence based on empirical data [8-11].

A change in the viscosity and specific volume leads to a change in the flow velocity, hence a change in the Reynolds number. After heating in the oil heater, the fuel has a specific gravity $\gamma^{\prime}$ and a kinematic viscosity coefficient $v^{\prime}$. The calculation of the hydraulic characteristics of the fourth section is carried out similarly to the calculation of the second section by obtaining new values $i^{\prime}, \lambda^{\prime}, R e^{\prime}, \omega^{\prime} .[12-15]$

Equivalent length of local resistances of the fourth section:

where :

$$
l_{\ni I V}=\sum \zeta_{k} \frac{d}{\lambda^{\prime}}
$$

$\zeta_{k}$ - coefficients of local resistances that are part of the fourth section. The reduced length of the fourth section will be defined as:

where:

$$
l_{n p I V}=l_{I V}+l_{I V}
$$

$l_{I V}$ is the length of the pipeline of the fourth section;

There will be a loss of pressure in the fourth section.

The fuel pressure behind the oil heater will be:

$$
\nabla p_{I V}=i^{\prime} l_{n p I V}
$$

$$
p_{I V}=p_{I I I}-\nabla p_{I V} \gamma^{\prime}
$$

Before modeling the fourth section of the pipeline, it is necessary to build a mathematical model of the fuel filter. The boiler-turbine power plant fuel filter is a coarse slotted filter. The cleaning fineness is $0.04-0.05 \mathrm{~mm}$. The main characteristics of the fuel filter include: the thickness of the spacer $\sigma$, which determines the size of the filter gap; the inner diameter 
of the rim of the filter plates $d_{B H}$; the number of spacers that determine the number of filter gaps $n$. The hydraulic resistance of the filter can be calculated according to [7]

where:

$$
\nabla p_{\phi}=\left(\frac{Q_{m o n л} v^{\prime 0,54}}{9,5 F_{\phi} \gamma^{\prime} d_{B H}^{0,6}}\right)^{1,18}
$$

$F_{\phi}=0,7 \pi d_{B H} \sigma n$ - cross-section of the fuel filter passageways;

$\mathrm{Q}_{\text {топл }}$ - fuel consumption, $\mathrm{kg} / \mathrm{min}$;

$\sigma$ - the value of the filter gap between the plates, see for most domestic filters $\sigma=0.12$ $\mathrm{mm}$;

$\gamma^{\prime}$ - specific weight of fuel, $\mathrm{kg} / \mathrm{l}$;

$v^{\prime}$ is the kinematic viscosity coefficient of the fuel, $\mathrm{cm}^{2} / \mathrm{s}$.

The pressure behind the filter is determined from the pressure difference at the end of the fourth section and the pressure drop on the fuel filter:

$$
p_{I V}^{\prime}=p_{I V}-\nabla p_{\phi}
$$

Modeling of the fifth section of the fuel system:

The fuel parameters in the fifth section correspond to the fuel parameters in the fourth section. The hydraulic characteristics of the fifth section are calculated using the values $i^{\prime}$, $\lambda^{\prime}$. Equivalent length of local resistances of the fifth section:

where:

$$
l_{\ni V}=\sum \zeta_{m} \frac{d}{\lambda^{\prime}}
$$

$\zeta_{m}$ - coefficients of local resistances that are part of the fifth section of the fuel pipeline

The reduced length of the fifth section will be defined as:

where:

$$
l_{n p V}=l_{V}+l_{\ni}
$$

$l_{V}$ is the length of the pipeline of the fifth section;

The pressure loss in the fifth section will be:

$$
\nabla p_{V}=i^{\prime} l_{n p V}
$$

The fuel pressure in front of the control panel will be:

$$
p_{V}=p_{I I I}-\nabla p_{V} \gamma^{\prime}
$$

Hydraulic resistance of pipeline section of the fuel system from the fuel pump to control burning will be:

$$
\nabla h=\left(\nabla p_{I I}+\nabla p_{I I I}+\nabla p_{I V}+\nabla p_{V}+\frac{\nabla p_{\phi}}{\gamma^{\prime}}\right)
$$

The potential energy reserve of the fuel system of the power plant is determined by the difference between the static pressure generated by the fuel pump and the required static pressure to ensure the fuel pressure in front of the combustion panel is not lower than the set value. The required pressure will be

where:

$$
H_{\text {потр }}=k_{\text {зап }} p_{p 2} / \gamma^{\prime}
$$

$p_{p 2}$ - the lower limit pressure of the fuel to control combustion, which provides sustainable management burning; available static pressure before control burning:

Potential energy reserve of the fuel system:

$$
H_{\text {pacп }}=p_{V} / \gamma^{\prime}
$$

$$
\nabla h_{\text {cuсm }}=H_{\text {расп }}-H_{\text {потр }}
$$

Then, if we denote the ratio of the required static head to the developed static head for the mixer's resistance coefficient $\mu_{c M}$, then the fuel pressure value after processing in the mixer-homogenizer, which will ensure stable control of the fuel pressure at all loads of the boiler with a reserve coefficient of at least $20 \%$, will be determined: 


$$
p_{1}=\mu_{c M} p_{0}
$$

\section{Conclusions}

Thus, because of constructing a mathematical model of the fuel pipeline, it was determined that a hydrodynamic mixer-homogenizer can be installed at the beginning of the second section of the fuel system. Calculation of the mathematical model of the fuel pipeline section allows to get the initial data for calculating the mixer-homogenizer that provides processing of fuel supplied to the boiler in all modes of operation of the boiler-turbine power plant. The indicator of the possibility of using a hydrodynamic mixer is the coefficient of resistance of the mixer $\mu_{c м}$ : the lower the value of $\mu_{c m}$, the greater the potential energy reserve of the fuel system under consideration for ensuring the operation of the mixer. The proposed developed design of the fuel pipeline allows using the kinetic energy of the flow to optimize the physical and chemical properties of the fuel.

\section{References}

1. Kotov V. S., Kharin A. Yu., Novikov A. G., Reznikova R. K. UMS-2018. - P. 53-58.

2. Kotov V. S., Reznikova R. K. Proceedings of the international scientific and technical conference (October 17-19, 2018) 2019. - P. 48-54

3. Lifshits L. I. - L. : [B. I.], 1961. - 20 p.

4. Loskutov V. V. - L.: Sudprom GIZ, 1963. - 311 p.

5. Losikov B. V. (ed.). Handbook. - M.: Chemistry, 1966. - 776 p.

6. $\quad$ Kulagin Yu.M., Kapustina T.I., Cherkassky V.M. Ivanovo state University, 1976. - 69 p.

7. Bashta T. M. M: Mashinostroenie, 1971. $-672 \mathrm{p}$.

8. Zulkifli Syafiq, Othman Fahmi, Omar. I Awad and Abdullah Adam MATEC Web Conf., 90 (2017) 01022

9. Crowe, T., Int. J. Multiphase Flow 26 (2000) 719-727.

10. Gatski, T.B. and Speziale, C.G., J. Fluid Mech. 254 (1993) 59-78.

11. Gökalp, I., Chauveau, C., Simon, O. and Chesneau, X., The Combustion Institute (1992)

12. Rodi, W., ZAMM 56 (1976) 219.

13. Sirignano, W.M., Cambridge University Press, Cambridge (1999).

14. Sadiki, A., Chrigui, M., Janicka, J. et al. Flow Turbulence Combust 75, 105-130 (2005).

15. Kim, W., Yu, T. \& Yoon, W. J Mech Sci Technol 26, 1781-1791 (2012). 